\title{
LOCAL AND REGIONAL MICROGRID MODELS TO OPTIMISE THE DESIGN OF ISOLATED ELECTRIFICATION PROJECTS
}

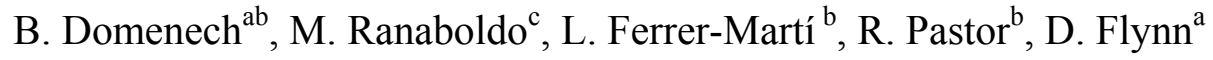 \\ ${ }^{a}$ Energy Institute, School of Electrical and Electronic Engineering, University College Dublin (Ireland) \\ ${ }^{b}$ Industrial Engineering and Logistics Group, Universitat Politècnica de Catalunya (Spain) \\ ${ }^{c} A W S$ Truepower (Spain) \\ *Corresponding author: bruno.domenech@upc.edu
}

\begin{abstract}
Wind-photovoltaic stand-alone electrification systems are a suitable option to provide electricity to isolated villages, in the right context of rural areas far from the national grid. Many initiatives promote electrification projects in rural areas spread across a territory; generally considering each village independently, implementing local microgrids. However, for the case of several neighbouring villages, a regional microgrid connecting them together may reduce costs. Determining the optimal design requires solving complex optimisation combinatorial problems to explore possible generator combinations and microgrid connections. In order to find the solution, a two-scale procedure is proposed: first, a local-scale mathematical model is developed to design a microgrid for each village; and then, a regional-scale model is proposed to design a microgrid connecting the villages together. Both models minimise the lifecycle costs and optimise supply quality, while considering the electrical requirements of end-users and solving for the location of equipment and the microgrid structure. For its validation, the two-scale procedure is considered for five small villages in La Rioja (Northern Spain); according to an Administration request to promote electrification for rural development. As a result, an optimised regional microgrid is proposed, supplying the five villages together, using medium voltage lines between them and low voltage lines internally, with generators centrally located on a windier mountain peak.
\end{abstract}

Keywords: case study; rural electrification; wind-photovoltaic; microgrid; mathematical modelling.

\section{Introduction}

Nowadays, around 1.1 billion people have no electricity access, mainly in rural and remote areas. These regions are generally characterised by small and scattered villages, where extending the national electricity grid would be too expensive and introduce significant technical problems such as unacceptable voltage drops. Alternatively, stand-alone systems based on renewable energy are in many cases economically, technically, socially and environmentally adequate [Ubilla et al., 2014]. In fact, the use of such systems is expected to double from now until 2030 within the EU27 countries [Ruiz-Romero et al., 2013]. Such systems have been used for: re-settling abandoned villages [Katiraei et al., 2007]; gridconnecting facilities for household electrical self-sufficiency [Colmenar-Santos et al., 2012]; reaching isolated poor areas in developing countries [Domenech et al., 2014]; or providing electricity to remote communities in developed countries [Rezaei \& Dowlatabadi, 2015].

In renewable energy-based electrification projects, solar photovoltaic (PV) generation is a promising and commonly applied technology [Khatib et al., 2016]. More specifically, its combination with wind energy is a favourable alternative, since both resources generally complement each other, improving supply reliability [Zhou et al., 2010; Bhattacharjee \& Acharya, 2015]. At the distribution level, microgrids that concentrate equipment at a single location to supply all the demand nodes of a village are progressively being deployed [Ferrer- 
Martí et al., 2012; Hossain et al., 2014]. Such configurations have advantages over individual supplies, such as better supply quality, lower investment costs due to economies of scale and a capability to deal with demand growth [Bhoyar \& Bharatkar, 2012; Azimoh et al., 2017].

Many projects use wind-PV microgrids to reach isolated rural communities worldwide [Ranaboldo et al., 2014; Schnitzer et al., 2014; Bahramara et al. 2016]. Africa has the largest rural electrification needs, and most countries are engaged within the United Nations program "Sustainable Energy for All", aiming to ensure universal electricity access using renewable energy [SE4All, 2014]. Latin America is a region where many efforts have been undertaken during the last years for rural electrification, but higher investment is typically necessary [Castilla et al., 2014]. The BRICS (Brazil, Russia, India, China and South Africa) countries are characterised by very large populations and enormous territories. Their efforts to extend electricity access and deal with demand increases using stand-alone renewable energy microgrids are noteworthy [Pereira et al., 2011; Bortolini et al., 2015]. In Australia, Canada and USA, with very large inhabited territories, such projects have been used to reach isolated areas [Dalton et al., 2009; Huang et al., 2011; Rezaei \& Dowlatabadi, 2015]. In Europe, renewable energy microgrids have been used in Spain [Bueno \& Carta, 2006], Germany, Netherlands and Portugal [Barnes et al., 2007], Greece [Giannoulis \& Haralambopoulos, 2011], Iceland [Chade et al., 2015] and Scotland [Chmiel \& Bhattacharyya, 2015].

When addressing the electrification of remote areas with several villages, generally independent solutions are conceived [Pereira et al., 2011]: for example, connecting all the demand nodes of a village into a single microgrid in order to improve supply quality, but without considering inter-village connections. However, if several non-electrified villages are spread across a territory, a regional microgrid connecting all villages together could reduce project costs, while the combined population would gain bargaining strength from pursuing the same objectives instead of each village looking after their own interests. Indeed, under the appropriate bargaining framework, the interconnection of local microgrids has proven to minimise social costs by taking advantage of renewable energy potentials at each location [Wang \& Huang, 2016] and can even leverage the spatiotemporal diversity of renewable generation and load profiles [Wang \& Huang, 2017b]. The operation of the system has been very studied in the literature [Singh et al. 2016; Gandini \& de Almeida, 2017], while identifying the optimal design solution requires solving a complex optimisation combinatorial problem to explore possible generator combinations, as well as possible node connections through local and regional microgrids. Different investigations and decision-making tools have been developed focusing on the generation option design (see Gamarra \& Guerrero [2015], Krishna \& Kumar [2015], Rojas-Zerpa \& Yusta [2015] and GIZ [2017] for recent reviews). Among all, HOMER is the most well-known [Bahramara et al. 2016].

However, very little research focuses on the detailed design of distribution microgrids in rural areas, simultaneously defining the size and location of the equipment used. Exceptionally, ViPOR [Lambert \& Hittle, 2000] addresses that problem although with some weaknesses: voltage drops are not considered and the solving process is based on a non-exact heuristic algorithm (simulated annealing), while heuristics can overstate results for large distances 
between nodes [Abdul-Salam \& Phimister, 2016]. In this sense, Ferrer-Martí et al. [2013] developed an exact Mixed Integer Linear Programming (MILP) model to design such systems, overcoming the aforementioned limitations. The model minimises upfront investment costs while sizing and siting generation and distribution equipment, according to the energy and peak power demand requirements as well as renewable resources availability. Domenech et al. [2015] extended such model including social constraints related to the design of electrification projects in developing countries. However, in both papers, only a single village is considered and generators can be installed only at demand nodes, without exploring nearby (external) high resource locations.

In this context, this work aims to develop a generalised process to design regional renewable energy-based stand-alone electrification projects. More specifically, a two-scale procedure is proposed, which has shown benefits to optimise the design of wind-PV-diesel microgrids [Wang \& Huang, 2017a]. In particular, two MILP models are developed for this purpose: a local-scale model to design an independent microgrid for each village and a regional-scale model to design a microgrid connecting the villages together. Both models aim to minimise lifecycle costs (investment, maintenance, replacement and salvage) as well as to optimise supply quality, through minimising voltage drops. As solution, both models define in detail the size and location of the generation, storage and distribution equipment to be implemented. In addition, the local-scale model includes possible generator locations at demand nodes and windy locations in the village surroundings, seeking a balance between generation close to demand, reducing line extension costs, or far from demand, taking advantage of high wind resource areas. The internal distribution microgrid is optimised considering low voltage (LV) lines. On its behalf, the regional-scale model includes possible generator locations far from villages but at areas having a strong wind resource. Connections between generators and villages are optimised considering medium voltage (MV) lines.

For its validation, the aforementioned two-scale design procedure is used to design an electrification project for Jubera valley, located in La Rioja (Northern Spain); according to a Local Administration initiative to re-settle five small villages using electrification to promote rural development. The procedure responds to the real needs of project developers when addressing isolated renewable energy-based electrification projects in a regional rural context.

The remainder of the paper is organised as follows. In Section 2, a technical description of the problem and the solving process for the two-scale design procedure are presented. In Section 3, the generalised local and regional MILP models are introduced. In Section 4, the Jubera valley is described. In Section 5, the two-scale procedure is used to design the electrification project for the Jubera Valley. Finally, in Section 6, the main conclusions are summarised.

\section{Two-scale design procedure}

In this section, first, a technical description of the problem is provided and, then, the solving process proposed for the two-scale design procedure is presented. 


\subsection{Technical description of the problem}

The overall structure of the stand-alone electrification projects being examined is shown in Figure 1. Generators (wind turbines and PV panels) supply electricity to demand nodes. The energy availability from wind turbines depends on each location due to wind variability. In contrast, solar radiation can be considered realtively uniform [Gueymard \& Wilcox, 2011]. The number of generators that can be installed at the same node is limited for space reasons and, for wind turbines, to avoid wake effects from installing them too close to each other. Batteries store energy to cover the mismatch between generation and consumption. The period without available generation production (to be supplied by batteries) is the selfsufficiency. Inverters transform the DC battery current into AC current, which is more suitable for many electrical appliances. Electricity is then distributed using LV lines for short distances, up to a maximum length to avoid excessive technical issues. For medium distances, MV lines are used and transforrmers become necessary to increase or decrease the voltage. Finally, microgrids typically have a radial typology [Lambert \& Hittle, 2000] to reduce costs. Single-phase lines are assumed, working at a frequency and voltage that can be pre-defined, depending on the country requirements.

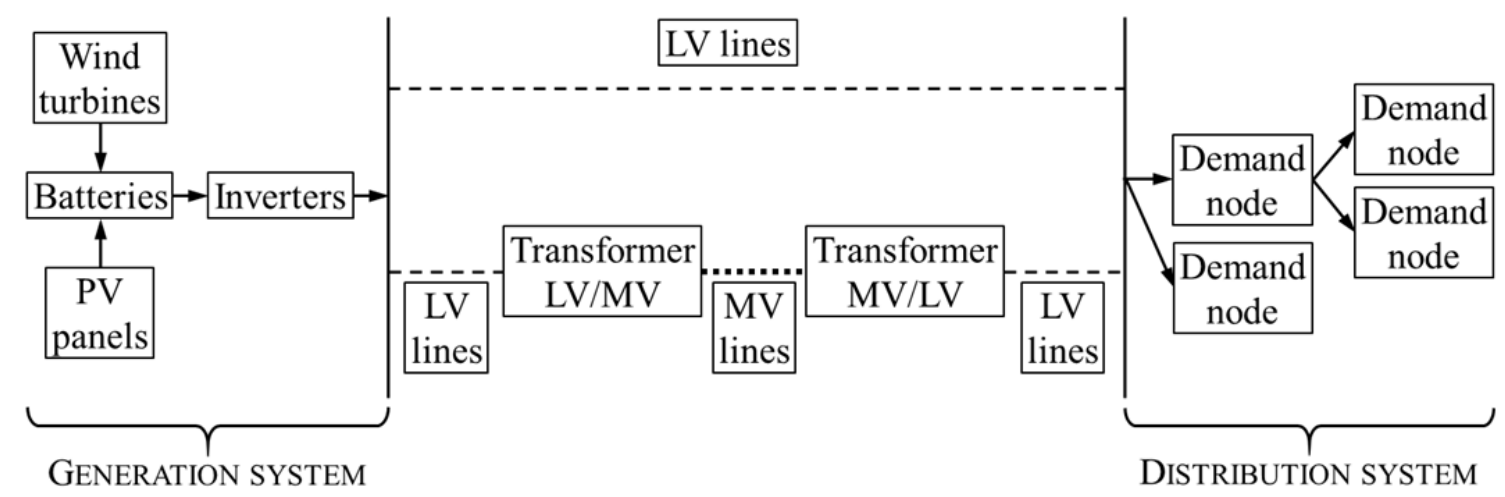

Figure 1. Scheme of elements for stand-alone electrification projects

In this work, three different locations for the generation system are distinguished:

- Demand nodes: village houses or buildings requiring electricity. Generators can be placed close to their location, sheltering batteries and inverters inside. LV lines are used within villages to completely connect all demand nodes through a local microgrid.

- Local nodes: points located in the village surroundings, seeking a balance between the wind potential, significantly higher than in demand nodes, and proximity, allowing the use of LV lines to reach demand nodes. A special building must be constructed close to generators to shelter batteries and inverters, incurring additional costs (fixed, for construction purposes, and variable, depending on the volume of equipment sheltered). Although installation and maintenance activities can be more complicated than for demand nodes due to distance issues, the negative effects of wind turbines for the population (such as noise and visual impact) are reduced. Besides, local nodes are typically located on nearby mountain hills, where average wind speeds are higher than in villages. 
- Regional nodes: points located far away from village centres but taking advantage of very windy areas. A nearby building for sheltering purposes is needed. The connection between regional nodes and villages is achieved through a regional microgrid, using MV lines and appropriate transformers to avoid excessive technical issues related to LV.

\subsection{Solving process for the two-scale design procedure}

This work proposes a two-scale design procedure to design an electrification system for a set of nearby villages located within a region. For this purpose, two MILP models (local and regional) are developed to solve for the location and size of generation and distribution equipment, minimising lifecycle project costs and optimising supply quality. Thus, the solving process is as follows. First, a local microgrid is defined separately for each village using the local-scale model, which forces all demand nodes to be connected into the same LV microgrid. The generation system can be located at the demand node that minimises microgrid voltage drops (to optimise supply quality) or at a nearby windy location (local nodes). MV lines and transformers are not included (Figure 1), as local-scale distances between points are relatively short. Second, a regional microgrid is designed using the regional-scale model, which forces the villages to be connected into the same microgrid, with generation potentially placed at very windy locations (regional nodes). The connection between such nodes and villages is achieved through MV lines, using appropriate transformers. In this model, each village is considered as a single location (hereinafter "village node"), placed at the demand node that minimises local microgrid voltage drops and with a demand equal to the sum of demands of the village.

\section{System design optimisation models}

In this section, the local-scale (Section 3.1) and regional-scale (Section 3.2) optimisation models are introduced.

\subsection{Local-scale optimisation model}

In the following sections, the data, variables, objective function and constrains of the localscale model are shown. As mentioned in Section 1, MILP models have been developed in the literature as a powerful tool to solve simplified versions of the problem [Ferrer-Martí et al., 2013]. The model here presented includes, in addition to technical considerations, the specific characteristics to address the new problem to be solved: (a) lifecycle costs are here considered, instead of only investment costs; (b) supply quality is here optimised; (c) generators can be here installed at windy locations in the village surroundings (local nodes), in addition to demand nodes. 
Table 1. List of input data for the local-scale model



${ }^{1}$ Interest rate: money devaluation over time. Discount rate: cost reductions (technology improvements, etc.).

${ }^{2}$ Equipment: wind turbines (WT), solar PV panels (PV), batteries (BAT), inverters (INV) and LV lines (LV).

${ }^{3}$ Inverters: the maintenance cost is generally negligible [Dufo-López et al., 2011].

${ }^{4}$ LV lines: longer lifecycle than project duration and salvage costs not considered [Dufo-López et al., 2011].

Table 2. List of variables for the local-scale model

\begin{tabular}{|c|c|l|l|}
\hline Category & \multicolumn{1}{|c|}{ Naming } & \multicolumn{1}{|c|}{ Definition } & \multicolumn{1}{|c|}{ Index definition } \\
\hline \multirow{2}{*}{$\begin{array}{c}\text { Integer } \\
\text { non-negative }\end{array}$} & $\begin{array}{c}x_{p, w}^{W T}, x_{p, s}^{P V} \\
x_{p, b}^{B A T}, x_{p, i}^{I N V}\end{array}$ & $\begin{array}{l}\text { Number of equipment units }{ }^{5} w / s / b / i \text { placed at } \\
\text { node } p\end{array}$ & $\begin{array}{l}p \in N^{A L L}, w \in N^{W T}, s \in N^{P V} \\
b \in N^{B A T}, i \in N^{I N V}\end{array}$ \\
\hline \multirow{3}{*}{$\begin{array}{c}\text { Float } \\
\text { non-negative }\end{array}$} & $e_{p, d}^{F L O W}, p_{p, d}^{F L O W}$ & $\begin{array}{l}\text { Energy [Wh/day] and power [W] flow at peak } \\
\text { load between nodes } p \text { and } d\end{array}$ & $p \in N^{A L L} ; d \in N_{p}^{D O W N}$ \\
\cline { 2 - 5 } & $v_{p}$ & Voltage [V] at node $p$ & $p \in N^{A L L}: V^{M I N} \leq v_{p} \leq V^{M A X}$ \\
\cline { 2 - 5 } Binary & $v_{p, d}$ & Voltage drop between connected nodes $p$ and $d$ & $p \in N^{A L L} ; d \in N_{p}^{D O W N}$ \\
\cline { 2 - 5 } & $u_{p}^{G E N} \in\{0,1\}$ & 1, iff at least one generator is placed at node $p$ & $p \in N^{A L L}$ \\
\hline \multirow{2}{*}{$u_{p, d, l}^{L V} \in\{0,1\}$} & 1, iff an LV line $l$ directly connects nodes $p$ and $d$ & $p \in N^{A L L} ; d \in N_{p}^{D O W N} ; l \in N^{L V}$ \\
\hline
\end{tabular}

${ }^{5}$ Equipment: wind turbines (WT), solar PV panels (PV), batteries (BAT) and inverters (INV). 


\subsubsection{Data}

The data (Table 1) represents information needed to realise the problem. The data is only listed here; while in Section 4.3 its estimation regarding the case study is provided.

\subsubsection{Variables}

The variables (Table 2) represent the information to be determined from the problem solution.

\subsubsection{Objective function}

The objective function (1) minimises lifecycle costs (investment, maintenance, replacement and salvage) while optimising supply quality. Considering lifecycle instead of only upfront investment costs aims to enhance decisions taken, as upfront cheaper solutions can become more expensive across the project lifetime. However, lifecycle costs must be updated to the present value, as explained later in this section. In addition, supply quality is optimised by minimising voltage drops between microgrid nodes. The aim is not to modify the solution cost, but to improve the efficiency of the solution finally obtained; so the parameter $\alpha$ is included to weight costs $(€)$ against voltage drops (V). Its value must ensure that the voltage drop term is sufficiently smaller than the lifecycle cost term. A detailed explanation on the estimation of the $\alpha$ parameter is included at the end of Section 4.3 for the case study analysed in this paper.

$$
[M I N] Z=C^{I N V S T}+C_{\text {present_value }}^{M N T}+C_{\text {present_value }}^{R P L}-C_{\text {present_value }}^{S L V}+\alpha \sum_{p \in N^{A L L}} \sum_{d \in N_{p}^{\text {DOWN }}} \Delta v_{p, d}
$$

Investment costs (1.1) represent the purchase of wind turbines, solar PV panels, batteries, inverters, LV lines and additional buildings installed. For the buildings, the cost is calculated as the sum of a fixed cost, representing materials transportation, workforce, terrain flattening and other construction activities; and a variable cost, which depends on the number of batteries and inverters sheltered as the building will be progressively larger.

$$
\begin{aligned}
C^{I N V S T}= & \sum_{p \in N^{A L L}} \sum_{w \in N^{W T}} x_{p, w}^{W T} C_{w}^{W T \_i n v s t}+\sum_{p \in N^{A L L}} \sum_{s \in N^{P V}} x_{p, s}^{P V} C_{s}^{P V \_i n v s t}+\sum_{p \in N^{A L L}} \sum_{b \in N^{B A T}} x_{p, b}^{B A T} C_{b}^{B A T_{-} i n v s t}+ \\
& \sum_{p \in N^{A L L}} \sum_{i \in N^{I N V}} x_{p, i}^{I N V} C_{i}^{I N V-i n v s t}+\sum_{p \in N^{A L L}} \sum_{d \in N_{p}^{D O W N}} \sum_{l \in N^{L V}} u_{p, d, l}^{L V} D_{p, d}^{N O D E} C_{l}^{L V \_i n v s t}+ \\
& \sum_{p \in N^{L O C}}\left[u_{p}^{G E N} C^{B U I L D_{-} f i x}+\left(\sum_{b \in N^{B A T}} x_{p, b}^{B A T}+\sum_{i \in N^{I N V}} x_{p, i}^{I N V}\right) C^{B U I L D_{-} v a r}\right]
\end{aligned}
$$

Maintenance costs (1.2) represent the yearly expense to ensure wind turbines, solar PV panels, batteries and LV lines functioning (cleaning, repairs, etc.). As such costs will be incurred across the whole project, they must be standardised to the present value using a capital recovery factor. This factor is calculated with the interest and discount rates as well as the project lifecycle (second braces in (1.2)) [Thiam, 2010; Agarwal \& Kumar, 2013]. 


$$
\begin{aligned}
& C_{\text {present_value }}^{M N T}=\left\{\sum_{p \in N^{A L L}} \sum_{w \in N^{W T}} x_{p, w}^{W T} C_{w}^{W T_{-} m n t}+\sum_{p \in N^{A L L}} \sum_{s \in N^{P V}} x_{p, s}^{P V} C_{s}^{P V_{-} m n t}+\sum_{p \in N^{A L L}} \sum_{b \in N^{B A T}} x_{p, b}^{B A T} C_{b}^{B A T_{-} m n t}+\right. \\
&\left.\sum_{p \in N^{A L L}} \sum_{d \in N_{p}^{D D W N}} \sum_{l \in N^{L V}} u_{p, d, l}^{L V} D_{p, d}^{N O D E} C_{l}^{L V_{-} m n t}\right\}\left\{\left(\frac{1+\rho^{I N T}}{\rho^{D I S C}-\rho^{I N T}}\right)\left[1-\left(\frac{1+\rho^{I N T}}{1+\rho^{D I S C}}\right)^{L^{P R J}}\right]\right\}
\end{aligned}
$$

Replacement costs (1.3) represent substitutions in wind turbines, solar PV panels, batteries and inverters exceeding their lifecycle. This function is calculated as the sum of expenses relating to the substitution of each specific equipment at each specific moment, updated to the current value through the net present value (in brackets in (1.3)) [Thiam, 2010; Agarwal \& Kumar, 2013]. Considering the example of wind turbines (WT), $L^{P R J} / L_{w}{ }^{W T}$ units are required across the project but the initial one is included in the investment function, so $L^{P R J} / L_{w}{ }^{W T}-1$ replacements are required. In addition, as $L^{P R J} / L_{w}{ }^{W T}$ can take float values, it is rounded up to an integer value $\left(\left\lceil L^{P R J} / L_{w}^{W T}\right\rceil\right)$.

$$
\begin{aligned}
& C_{\text {present_value }}^{R P L}=\sum_{p \in N^{A L L}} \sum_{w \in N^{w T}} \sum_{t=1}^{\left[\frac{L^{P R J}}{L_{w}^{W T}}\right]^{-1}} x_{p, w}^{W T} C_{w}^{W T}{ }_{-}^{\text {invst }}\left(\frac{1+\rho^{I N T}}{1+\rho^{D I S C}}\right)^{t \cdot L_{w}^{W T}}+\sum_{p \in N^{A L L}} \sum_{s \in N^{P V}} \sum_{t=1}^{\left[\frac{L^{P R J}}{L_{s}^{P V}}\right]^{-1}} x_{p, s}^{P V} C_{s}^{P V}{ }_{-}^{i n v s t}\left(\frac{1+\rho^{I N T}}{1+\rho^{D I S C}}\right)^{t \cdot L_{s}^{P V}}+ \\
& \sum_{p \in N^{A L L}} \sum_{b \in N^{B A T}} \sum_{t=1}^{\left[\frac{L^{P R J}}{L_{b}^{B A T}}\right]} x_{p, b}^{B A T} C_{b}^{B A T \_i n v s t}\left(\frac{1+\rho^{I N T}}{1+\rho^{D I S C}}\right)^{t \cdot L_{b}^{B a T}}+\sum_{p \in N^{A L L}} \sum_{i \in N^{N N V}} \sum_{t=1}^{\left[\frac{L^{P R J}}{L_{i}^{N V}}-1\right.} x_{p, i}^{I N V} C_{i}^{I N V \_i n v s t}\left(\frac{1+\rho^{I N T}}{1+\rho^{D I S C}}\right)^{t \cdot L_{i}^{I N V}}
\end{aligned}
$$

Salvage costs (1.4) represent the marginal value of wind turbines, solar PV panels, batteries and inverters at project end. As before, the net present value (in brackets in (1.4)) is used to standardise costs [Thiam, 2010; Agarwal \& Kumar, 2013], considering the excess value when the project ends. Following with the example of wind turbines, $\left\lceil L^{P R J} / L_{w}^{W T}\right\rceil$ units are needed across the project, but those used $L^{P R J} / L_{w}{ }^{W T}$ (not rounded) are discarded.

$$
\begin{aligned}
& C_{p r e s e n t \_ \text {value }}^{S L V}=\left\{\sum_{p \in N^{A L L}} \sum_{w \in N^{n T}} x_{p, w}^{W T} C_{w}^{W T}{ }_{-}^{i n v s t}\left(\left\lceil\frac{L^{P R J}}{L_{w}^{W T}}\right\rceil-\frac{L^{P R J}}{L_{w}^{W T}}\right)+\sum_{p \in N^{A L L}} \sum_{s \in N^{P V}} x_{p, s}^{P V} C_{s}^{P V}{ }_{-i n v s t}\left(\left\lceil\frac{L^{P R J}}{L_{s}^{P V}}\right\rceil-\frac{L^{P R J}}{L_{s}^{P V}}\right)+\right. \\
& \left.\sum_{p \in N^{A L L}} \sum_{b \in N^{B A T}} x_{p, b}^{B A T} C_{b}^{B A T}{ }_{-i n v s t}\left(\left\lceil\frac{L^{P R J}}{L_{b}^{B A T}}\right\rceil-\frac{L^{P R J}}{L_{b}^{B A T}}\right)+\sum_{p \in N^{A L L}} \sum_{i \in N^{I N V}} x_{p, i}^{I N V} C_{i}^{I N V_{-} i n v s t}\left(\left\lceil\frac{L^{P R J}}{L_{i}^{I N V}}\right\rceil-\frac{L^{P R J}}{L_{i}^{I N V}}\right)\right\}\left(\frac{1+\rho^{I N T}}{1+\rho^{D I S C}}\right)^{L^{P R J}}
\end{aligned}
$$

\subsubsection{Constraints}

The constraints represent technical issues for equipment. Constraints (2), (3) and (4) define generation nodes. If at least one wind turbine (2) or solar PV panel (3) is installed at a location, that node is defined as a generation node. Otherwise (4), it cannot be a generation node. In addition, the number of wind turbines (2) and solar PV panels (3) at the same location cannot exceed a maximum value, due to space limitations. 


$$
\begin{aligned}
& \sum_{w \in N^{W T}} x_{p, w}^{W T} \leq N^{W T}{ }^{M A X} u_{p}^{G E N} \\
& p \in N^{A L L} \\
& \sum_{s \in N^{P V}} x_{p, s}^{P V} \leq N^{P V-M A X} u_{p}^{G E N} \\
& p \in N^{A L L} \\
& \sum_{w \in N^{v T}} x_{p, w}^{W T}+\sum_{s \in N^{P V}} x_{p, s}^{P V} \geq u_{p}^{G E N} \quad p \in N^{A L L}
\end{aligned}
$$

Constraints (5) and (6) establish conditions for energy conservation. At demand nodes (5), the energy supplied (from an upstream line or installed generators) must be higher than or equal to the energy consumption (at that node, considering losses, and downstream nodes). The term in brackets allows for consideration of line efficiency only for nodes supplied through an LV line $\left(u_{p}^{G E N}=0\right)$. At local nodes (6), the same reasoning applies between the energy from generators and downstream nodes demand. The option "higher than" is included for modelling purposes, assuming the staggered nature of equipment available, although in practice supply excesses are balanced through a dump load system (generally a resistor dissipating energy in the form of heat).

$$
\begin{array}{cc}
\sum_{q \in N^{A L L} \mid p \in N_{q}^{D O W N}} e_{q, p}^{F L O W}+\sum_{w \in N^{W T}} x_{p, w}^{W T} E_{p, w}^{W T}+\sum_{s \in N^{P V}} x_{p, s}^{P V} E_{s}^{P V} \geq & \\
\frac{E_{p}^{D E M}}{\eta^{B A T} \eta^{I N V}}\left(\frac{1}{\eta^{L V}}+\left(1-\frac{1}{\eta^{L V}}\right) u_{p}^{G E N}\right)+\sum_{d \in N_{p}^{D D W N}} e_{p, d}^{F L O W} & p \in N^{D E M} \\
\sum_{w \in N^{W T}} x_{p, w}^{W T} E_{p, w}^{W T}+\sum_{s \in N^{P V}} x_{p, s}^{P V} E_{s}^{P V} \geq \sum_{d \in N_{p}^{D O W N}} e_{p, d}^{F L O W} & p \in N^{L O C}
\end{array}
$$

Constraints (7) and (8) are analogous to (5) and (6), but for the peak load condition. The maximum power at a node (limited from an upstream line or installed inverter) must be higher than or equal to the peak load (at that node, considering losses, and downstream nodes). Constraints (5) to (8) define the interdependence between flows on one line versus flows on other lines; the flow upstream of a node is related to the flow downstream of such a node.

$$
\begin{aligned}
& \sum_{q \in N^{A L L} \mid p \in N_{q}^{D D W N}} p_{q, p}^{F L O W}+\sum_{i \in N^{N V}} x_{p, i}^{I N V} P_{i}^{I N V} \geq P_{p}^{D E M}\left(\frac{1}{\eta^{L V}}+\left(1-\frac{1}{\eta^{L V}}\right) u_{p}^{G E N}\right)+\sum_{d \in N_{p}^{\text {DowN }}} p_{p, d}^{F L O W} \quad p \in N^{D E M} \\
& \sum_{i \in N^{I N V}} x_{p, i}^{I N V} P_{i}^{I N V} \geq \sum_{d \in N_{p}^{D D W N}} p_{p, d}^{F L O W}
\end{aligned}
$$

Battery capacity is sized in constraints (9) and (10) for demand and local nodes, respectively. The battery storage system aims to cover the demand requirements of population during periods in which the electricity supply may be interrupted (caused by cloudy or non-windy days, maintenance activities, etc.). Consequently, the battery capacity installed at a node must be higher than or equal to the energy demand at that node and downstream nodes, considering the system self-sufficiency and allowed depth of discharge. Batteries are located at generation nodes $\left(u_{p}^{G E N}=1\right)$; otherwise, both constraints remain inactive. 


$$
\begin{array}{ll}
\frac{D^{B A T}}{T^{D E M}} \sum_{b \in N^{B A T}} x_{p, b}^{B A T} E_{b}^{B A T}+\sum_{j \in N^{D E M}} \frac{E_{j}^{D E M}}{\eta^{B A T} \eta^{I N V} \eta^{L V}}\left(1-u_{p}^{G E N}\right) \geq \sum_{d \in N_{p}^{D D W N}} e_{p, d}^{F L O W}+\frac{E_{p}^{D E M}}{\eta^{B A T} \eta^{I N V}} & p \in N^{D E M} \\
\frac{D^{B A T}}{T^{D E M}} \sum_{b \in N^{B A T}} x_{p, b}^{B A T} E_{b}^{B A T}+\sum_{j \in N^{D E M}} \frac{E_{j}^{D E M}}{\eta^{B A T} \eta^{I N V} \eta^{L V}}\left(1-u_{p}^{G E N}\right) \geq \sum_{d \in N_{p}^{D D W N}} e_{p, d}^{F L O W} & p \in N^{L O C}
\end{array}
$$

Constraint (11) requires inverters to be installed only at generation locations. The term in brackets is a maximum boundary included for modelling purposes to relate an integer variable $\left(x_{p, i}^{I N V}\right)$ against a binary variable $\left(u_{p}^{G E N}\right)$.

$$
\sum_{i \in N^{I N V}} x_{p, i}^{I N V} \leq\left(\sum_{j \in N^{D E M}} \frac{P_{j}^{D E M}}{\eta^{L V}}\right) u_{p}^{G E N} \quad p \in N^{A L L}
$$

Constraints (12) and (13) link the energy and power flows to the existence of an LV line between each pair of nodes. The terms in brackets are included to relate float variables $\left(e_{p, d}^{F L O W}\right.$ and $\left.p_{p, d}^{F L O W}\right)$ against a binary variable $\left(u_{p, d, l}^{L V}\right)$.

$$
\begin{array}{ll}
e_{p, d}^{F L O W} \leq\left(\sum_{j \in N^{D E M}} \frac{E_{j}^{D E M}}{\eta^{B A T} \eta^{I N V} \eta^{L V}}\right)_{l \in N^{L V}} u_{p, d, l}^{L V} & p \in N^{A L L}, d \in N_{p}^{D O W N} \\
p_{p, d}^{F L O W} \leq\left(\sum_{j \in N^{D E M}} \frac{P_{j}^{D E M}}{\eta^{L V}}\right) \sum_{l \in N^{L V}} u_{p, d, l}^{L V} & p \in N^{A L L}, d \in N_{p}^{D O W N}
\end{array}
$$

Constraint (14) establishes a radial microgrid whereby each node can have a single upstream line or itself can be a generation node.

$$
\sum_{q \in N^{A L L} \mid p \in N_{q}^{\text {DOWN }}} \sum_{l \in N^{L V}} u_{q, p, l}^{L V}+u_{p}^{G E N} \leq 1 \quad p \in N^{D E M}
$$

The voltage at each node lies within the variable definition $\left(V^{M I N} \leq v_{p} \leq V^{M A X}\right)$. In addition, constraint (15) relates the voltage drop between each pair of connected nodes to their relative distance, the resistance of the line installed and the power flowing between them at peak load. Constraint (16) ensures that the rated current for the line is sufficient for the given power flow. Both constraints remain inactive if the pair of nodes are not directly connected.

$$
\begin{array}{ll}
v_{p}-v_{d} \geq \frac{D_{p, d}^{N O D E} R_{l}^{L V}}{V^{N O M}}\left(p_{p, d}^{F L O W}-\sum_{j \in N^{D E M}} \frac{P_{j}^{D E M}}{\eta^{L V}}\left(1-u_{p, d, l}^{L V}\right)\right) & p \in N^{A L L}, d \in N_{p}^{D O W N}, l \in N^{L V} \\
p_{p, d}^{F L O W}-\sum_{j \in N^{D E M}} \frac{P_{j}^{D E M}}{\eta^{L V}}\left(1-u_{p, d, l}^{L V}\right) \leq I_{l}^{L V} V^{N O M} & p \in N^{A L L}, d \in N_{p}^{D O W N}, l \in N^{L V}
\end{array}
$$


The voltage difference between two nodes $\left(v_{p}-v_{d}\right)$ takes a value, regardless of whether they are connected or not. In order to optimise supply quality and minimise voltage drops in the objective function (1), only voltage drops for nodes directly connected by an LV line must be considered. In (17) and (18) such a variable $\left(\Delta v_{p, d}\right)$ is considered. If two nodes $p$ and $d$ are not connected $\left(u_{p, d, l}^{L V}=0 ; l \in N^{L V}\right), \Delta v_{p, d}$ is zero. In addition, if an LV line $l$ supplies from node $p$ to $d\left(u_{p, d, l}^{L V}=1\right), \Delta v_{p, d}$ takes a value, while $\Delta v_{d, p}$ is zero.

$$
\begin{array}{ll}
\Delta v_{p, d} \geq v_{p}-v_{d}-\left(V^{M A X}-V^{M I N}\right)\left(1-\sum_{l \in N^{L V}} u_{p, d, l}^{L V}\right) & p \in N^{A L L}, d \in N_{p}^{D O W N} \\
\Delta v_{p, d} \leq\left(V^{M A X}-V^{M I N}\right) \sum_{l \in N^{L V}} u_{p, d, l}^{L V} & p \in N^{A L L}, d \in N_{p}^{D O W N}
\end{array}
$$

Finally, constraints (19) and (20) define that all demand nodes are supplied by the same microgrid, with generation placed at a demand node but not at local nodes. These two constraints can be substituted by (21) and (22) in order to force the opposite situation: all demand nodes supplied by the same microgrid, with generation placed at a local node but not a demand node. Indeed, this option is used in Section 5 in order to analyse the solution obtained when generators are located at demand or local nodes.

$$
\begin{aligned}
\sum_{p \in N^{D E M}} u_{p}^{G E N} & =1 \\
\sum_{p \in N^{L O C}} u_{p}^{G E N} & =0 \\
\sum_{p \in N^{D E M}} u_{p}^{G E N} & =0 \\
\sum_{p \in N^{L O C}} u_{p}^{G E N} & =1
\end{aligned}
$$

\subsection{Regional-scale optimisation model}

For the sake of clarity and consistency, the regional-scale model is presented following a similar approach to the local-scale model. However, demand nodes are substituted by village nodes, which are placed, for each village, at the demand node that minimises local microgrid voltage drops and whose demand is equal to the sum of demands of the village (Section 2.2). Modified constraints are indicated by an apostrophe, while new constraints use the same numbering scheme as before.

\subsubsection{Data}

Parameters relating to the project lifecycle $\left(L^{P R J}\right)$, interest and discount rates $\left(\rho^{I N T}, \rho^{D I S C}\right)$, voltage weighting parameter $(\alpha)$, self-sufficiency $\left(T^{D E M}\right)$, wind turbines $\left(N^{W T}, N^{W T_{-} M A X}\right.$, $\left.C_{w}^{W T \_i n v s t}, C_{s}^{W T} T_{-m n t}, L_{w}^{W T}\right)$, PV panels $\left(N^{P V}, N^{P V+M A X}, C_{s}^{P V-i n v s t}, C_{s}^{P V-m n t}, L_{s}^{P V}, E_{s}^{P V}\right)$, batteries $\left(N^{B A T}\right.$, 
$\left.C_{b}^{B A T_{-} i n v s t}, C_{b}^{B A T_{-} m n t}, L_{b}^{B A T}, E_{b}^{B A T}, D^{B A T}, \eta^{B A T}\right)$, inverters $\left(N^{I N V}, C_{i}^{I N V_{-} i n v s t}, L_{i}^{I N V}, P_{i}^{I N V}, \eta^{I N V}\right)$ and building $\left(C^{B U I L D_{-} f i x}, C^{B U I L D_{-} v a r}\right)$ remain unchanged. Wind turbines energy output $\left(E_{p, w}^{W T}\right)$ is defined for regional nodes, as in the local-scale model. LV line parameters $\left(N^{L V}, C_{l}^{L V}{ }^{i n v s t}, C_{l}^{L V}{ }^{m n t}, R_{l}^{L V}\right.$, $\left.I_{l}^{L V}, \eta^{L V}\right)$ are replaced by MV ones and voltages $\left(V^{N O M}, V^{M I N}, V^{M A X}\right)$ also represent MV. In addition, the parameters from Table 3 are included.

Table 3. List of input data for the regional-scale model

\begin{tabular}{|c|c|c|c|}
\hline Category & Naming & Definition & Index definition \\
\hline \multirow{3}{*}{ Nodes } & $N^{V I L}, N^{R E G}, N^{V R}$ & Set of village, regional and village-regional nodes & $N^{V R}=\left\{N^{V I L} \cup N^{R E G}\right\}$ \\
\hline & $D_{p, d}^{N O D E}$ & Distance $[\mathrm{m}]$ between nodes $p$ and $d$ & $p \in N^{V R}, d \in N^{V I L}: p \neq d$ \\
\hline & $N_{p}^{D O W N}$ & $\begin{array}{l}\text { Set of downstream nodes } d \text { that can be directly connected } \\
\text { by an MV line from node } p\end{array}$ & $p \in N^{V R} ; d \in N^{V I L}: p \neq d$ \\
\hline Demand & $E_{p}^{D E M_{-} V I L}, P_{p}^{D E M_{-} V I L}$ & Energy $[\mathrm{Wh} /$ day] and peak load $[\mathrm{W}]$ at village node $p$ & $p \in N^{V I L}$ \\
\hline Villages & $C_{p}^{V I L L_{-i n v s t}}, C_{p}^{V I L \_m n t}$ & $\begin{array}{l}\text { Investment }[€] \text { and maintenance [€/year] costs for the local } \\
\text { LV microgrid at village node } p\end{array}$ & $p \in N^{V I L}$ \\
\hline \multirow[b]{2}{*}{ Transformers } & $N^{T R F}, \eta^{T R F}$ & Available options and efficiency [unit fraction] & - \\
\hline & $C_{t}^{T R F_{-} \text {invst }}, L_{t}^{T R F}, P_{t}^{T R F}$ & Investment $\operatorname{cost}^{6}[€]$, lifecycle [years] and peak rating [VA] & $t \in N^{T R F}$ \\
\hline
\end{tabular}

${ }^{6}$ Transformers: the maintenance cost is generally negligible [Dufo-López et al., 2011].

\subsubsection{Variables}

Variables relating to the number of wind turbines $\left(x_{p, w}^{W T}\right)$, solar PV panels $\left(x_{p, s}^{P V}\right)$, batteries $\left(x_{p, b}^{B A T}\right)$, inverters $\left(x_{p, i}^{I N V}\right)$ and generation nodes $\left(u_{p}^{G E N}\right)$ are defined for regional nodes. In variables relating to the energy $\left(e_{p, d}^{F L O W}\right)$ and power $\left(p_{p, d}^{F L O W}\right)$ flows, voltage $\left(v_{p}\right)$ and voltage drops $\left(\Delta v_{p, d}\right)$, the $p$ and $d$ subscripts are defined for village-regional nodes. The variable relating to the existence of a line between two nodes $\left(u_{p, d, l}^{L V}\right)$ is replaced by a MV variable $\left(u_{p, d, l}^{M V}\right)$. In addition, the integer non-negative variable $x_{p, t}^{T R F}$ is included, representing the number of transformers $t$ placed at node $p\left(p \in N^{V R}, t \in N^{T R F}\right)$.

\subsubsection{Objective function}

The objective function slightly differs from the local-scale model (1). The main structure remains unchanged, including investment, maintenance, replacement and salvage costs as well as a weighted supply quality. However, the terms relating to LV lines are substituted by the investment $\left(C_{p}^{V L L_{-} i n v t}\right)$ and maintenance $\left(C_{p}^{V I L}{ }_{-}^{m n t}\right)$ costs of the local microgrids. In addition, MV lines are included in the investment and maintenance functions, while transformers are also added in the investment, replacement and salvage functions. The detailed objective function is shown is Appendix A. 


\subsubsection{Constraints}

Constraints relating to the definition of generation nodes ((2), (3) and (4)) remain unchanged but their scope of application is defined for regional nodes. Similarly, the scope of application of constraints relating to energy (6) and power (8) conservation as well as battery sizing (10) is changed from local to regional nodes. Constraints relating to energy (12) and power (13) flows as well as voltage drops ((15), (16), (17) and (18)) remain unchanged, but they refer to MV lines. In addition, constraint (5') establishes the conditions for energy conservation within village nodes. The energy supplied (from an upstream line) must be higher than (considering dump load) or equal to the energy consumption (of the village, considering losses, and downstream villages).

$\sum_{q \in N^{V R} \mid p \in N_{q}^{\text {DOWN }}} e_{q, p}^{F L O W} \geq \frac{E_{p}^{D E M}}{\eta^{B A T} \eta^{I N V} \eta^{M V}\left(\eta^{T R F}\right)^{2}}+\sum_{d \in N_{p}^{\text {DOWN }}} e_{p, d}^{F L O W} \quad p \in N^{V L L}$

Constraint ( $\left.7^{\prime}\right)$ is analogous to (5'), but for the peak load condition. The maximum power received at a village node (limited from an upstream line) must be higher than or equal to the peak load (at that village, considering losses, and downstream villages).

$\sum_{q \in N^{V R} \mid p \in N_{q}^{\text {DOWN }}} p_{q, p}^{F L O W} \geq \frac{P_{p}^{D E M}}{\eta^{M V}\left(\eta^{T R F}\right)^{2}}+\sum_{d \in N_{p}^{\text {DOWN }}} p_{p, d}^{F L O W} \quad p \in N^{V I L}$

Constraint (14') establishes a radial microgrid: each village node can have one upstream line.

$\sum_{q \in N^{V R} \mid p \in N_{q}^{\text {DOWN }}} \sum_{l \in N^{M V}} u_{q, p, l}^{M V} \leq 1$

Transformers are sized in constraint (23) for village nodes - whereby an MV/LV transformer is needed - and (24) for regional nodes - where an LV/MV transformer is included according to the power flowing at peak load between villages.

$$
\begin{array}{ll}
\sum_{t \in N^{T R F}} x_{p, t}^{T R F} P_{t}^{T R F} \geq \sum_{q \in N^{N R} \mid p \in N_{q}^{\text {DOWN }}} p_{q, p}^{F L O W}-\sum_{d \in N_{p}^{\text {DOWN }}} p_{p, d}^{F L O W} & p \in N^{V L L} \\
\sum_{t \in N^{T R F}} x_{p, t}^{T R F} P_{t}^{T R F} \geq \sum_{d \in N_{p}^{\text {DOWN }}} p_{p, d}^{F L O W} & p \in N^{R E G}
\end{array}
$$

\section{Analysis of Jubera valley}

The Jubera valley is one of the most inaccessible areas in La Rioja (Northern Spain), covering an area of $86 \mathrm{~km}^{2}$ and 186 inhabitants [INE, 2014]. Due to a lack of economic prospects and rural exodus, the population has been reduced to less than a sixth of 1950 levels. Most 
inhabitants live in three villages (Jubera, San Bartolomé and Santa Engracia del Jubera), already electrified through a national grid connection. The remaining population live in three small communities without electricity: San Martín, Santa Cecilia and Santa Marina, while Bucesta and El Collado are abandoned villages (Figure 2).

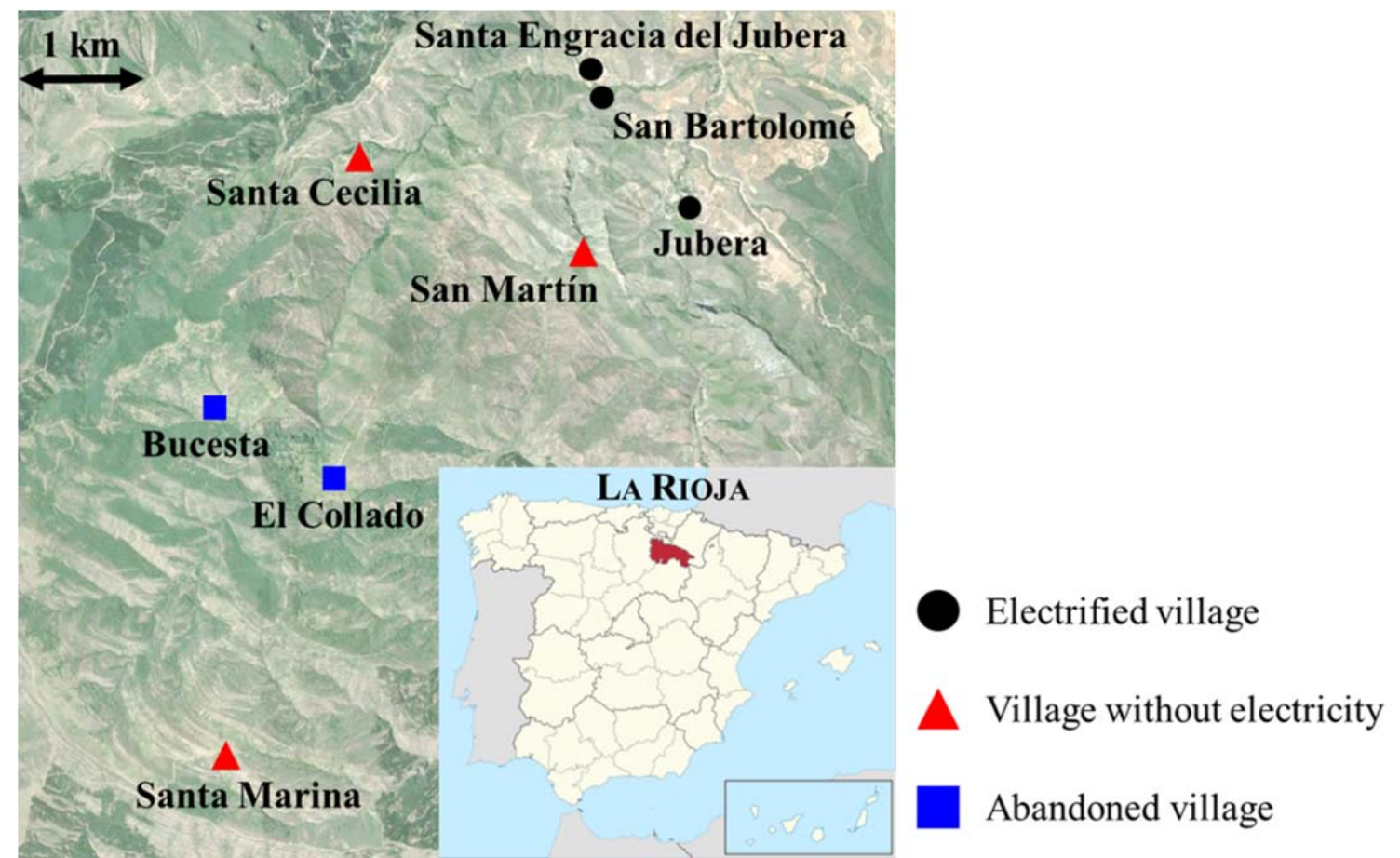

Figure 2. Location of the communities within the Jubera valley

It should be noted that although Santa Cecilia and San Martín seem to be close to the gridconnected villages, the practical challenges are daunting, as there are valleys and mountains between them. In fact, although the local authorities have attempted to promote the national electricity grid extension, the villages' remoteness and low population density have been a significant limitation for utility companies. Currently, those communities are not included within any government plan for grid extension. As an alternative, the Local Administration is studying the implementation of an off-grid renewable energy-based microgrid project, thus promoting the valley self-sufficiency. The project is accompanied by a repopulation plan with the purpose of re-establishing those villages and avoiding their abandonment. Demand, resources and technical assessments were carried out during valley visits and through interviews with inhabitants accompanied by Local Administration representatives.

Despite several attempts to extend the grid to the non-electrified villages, their remoteness and low population density have been a limitation for utility companies. Consequently, the Local Administration is promoting an electrification project through stand-alone renewable energy-based systems. The project is accompanied by a repopulation plan with the purpose of re-establishing those villages and avoiding their abandonment. Demand, resources and technical assessments were carried out during valley visits and through interviews with inhabitants accompanied by Local Administration representatives. 


\subsection{Demand assessment}

As demand nodes, the electrification project considers the occupied houses [INE, 2014] as well as some abandoned buildings in good condition that could be relatively easily restored (assessed together with Local Administration technicians), second homes and repopulation projects, such as in El Collado, where a community re-establishment initiative began a few years ago. As a result, 5 houses are considered in Bucesta, 13 in El Collado, 13 in San Martin, 11 in Santa Cecilia and 11 in Santa Marina.

Afterwards, a demand assessment was performed including inhabitant interviews, analysis of nearby village consumptions and future demand increases in order to determine the energy, peak power and self-sufficiency requirements of the population. The highest consumption period was considered, assuming that if the daily demand is covered in such months, it will also be covered for the rest of the year [Díaz et al., 2013; Hoque \& Kumar, 2013; Koussa et al., 2014]. The per capita consumption was identified to be higher in winter; although most houses have a larger number of occupants in summer, such that the overall demand is higher. Finally, the following requirements were defined according to the Local Administration:

- Energy: $3 \mathrm{kWh} /$ day. Consumption for lighting, telecommunications and some domestic devices/commodities.

- Peak power: $1.15 \mathrm{~kW}$. Contract offered by Spanish utility companies. No distinction between active and reactive power has been made, since after assessing end-user loads, reactive consumption is considered not significant.

- Self-sufficiency: 3 days. Enough value to ensure an acceptable security of supply.

\subsection{Resource assessment}

Spain is widely recognised as having a strong wind and solar potential [Ruiz-Romero et al., 2013]. Regarding the solar resource, spatial variations are not significant in areas up to $30 \times 30$ $\mathrm{km}^{2}$, even in mountainous regions [Gueymard \& Wilcox, 2011]. Therefore, solar radiation is here considered uniform across the region and evaluated using a NASA database, which collects data from meteorological stations worldwide [NASA, 2017]. For effective and robust design, the lowest resource month is considered, ensuring that the system will also meet the demand for the rest of the year. Thus, in December, the average temperature is $4.7^{\circ} \mathrm{C}$ and the solar radiation is 1.39 peak solar hours (daily hours exceeding a $1000 \mathrm{~W} / \mathrm{m}^{2}$ irradiation).

Regarding the wind resource, more detailed analysis is needed. The Spanish wind atlas is available in IDAE [2016], providing information about the seasonal mean wind speeds at different heights, with a grid spacing of $100 \mathrm{~m}$. IDEA [2016] used in-situ measurements to verify the adequacy of the wind atlas outputs. Thus, the wind climate for the Jubera valley has a dominant wind direction from the West and mean wind speeds ranging from 3.0 to $7.5 \mathrm{~m} / \mathrm{s}$ at a height of $30 \mathrm{~m}$, depending on the location (Figure 3). Generally, a lower resource is found in the valleys, while in elevated regions, such as mountain peaks, the resource is higher. The seasonal wind speed variation is around $40 \%$ across the year with higher values in winter relative to summer. 
As presented in Section 2, generators can be installed at three groups of nodes (Figure 3). First, at demand nodes. Bucesta and San Martín are located in areas with a very low wind potential, while Santa Cecilia is located in a medium resource zone, and El Collado and Santa Marina possess the highest wind resource. Second, at local nodes (local-scale analysis). A location in the surroundings of each village is defined, seeking a balance between the wind potential, significantly higher than within villages, and proximity to village centres. Third, at regional nodes (regional-scale analysis). Two locations at very windy central positions between the five communities are identified. It should be noted that when looking for the local and regional nodes, accessibility for installation and maintenance activities was sought, as well as flat terrains for equipment foundations. In some cases, vegetation would have to be removed, basically small bushes and scrubs not requiring excessive efforts. This is the reason why some of such nodes are not exactly located on highest wind locations, but close to them.

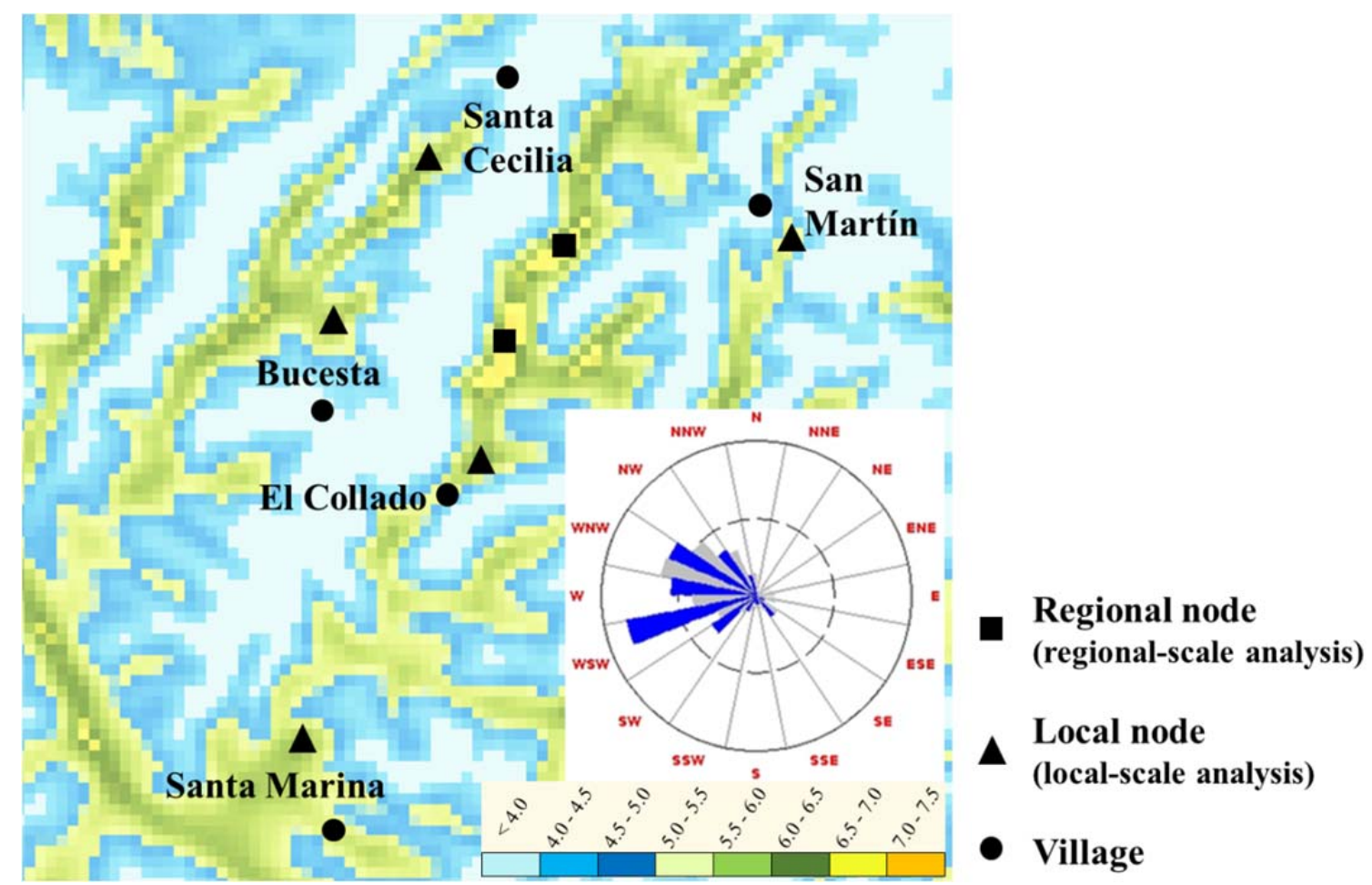

Figure 3. Wind resource map for Jubera valley

\subsection{Technical assessment}

The cost and technical characteristics of the equipment used are determined. Some data, subject to uncertainty (such as maintenance costs), are extrapolated from commercial products and previous project experiences. Six wind turbine options are considered due to their high economies of scale; while a smaller number is included for other devices.

- Project. Expected lifecycle: 20 years. Interest rate: 3\%. Discount rate: 4.5\%.

- Wind turbines (6 options). Rated power: $1 \mathrm{~kW} ; 3 \mathrm{~kW} ; 7.5 \mathrm{~kW} ; 10 \mathrm{~kW} ; 20 \mathrm{~kW}$ and $30 \mathrm{~kW}$. The energy supplied depends on the location, according to the wind assessment (Section 4.2) extrapolated to the hub height of each wind turbine option, ranging from 8 to $24 \mathrm{~m}$. 
Cost: $2,450 € ; 8,250 € ; 15,000 € ; 22,900 € ; 36,750 €$ and 53,300€. Maintenance cost: $2 \%$ of investment cost. Lifecycle: 20 years each. Maximum number at a node: 5 .

- Solar panels (2 options). Rated power: $100 \mathrm{~W}$ and $250 \mathrm{~W}$. The energy supplied depends on the location, according to the solar assessment (Section 4.2). Cost: $250 €$ and $500 €$. Maintenance cost: $1.5 \%$ of investment cost. Lifecycle: 25 years each. Maximum number at a node: 150 (according to space limitations in the surroundings of demand nodes).

- Batteries (2 options). Capacity: 11,040 Wh and 29,040 Wh. Cost: 1,860€ and 3,440€. Maintenance cost: $30 € /$ year each. Lifecycle: 4 and 7 years, respectively. Efficiency: 0.85 . Allowed depth of discharge: 0.70 of total capacity.

- Inverters (2 options). Rated power: $1,500 \mathrm{~W}$ and 5,000 W. Cost: 1,100€ and 2,650€. Lifecycle: 10 years each. Efficiency: 0.85 .

- LV lines (1 option). Cost: $4 € / \mathrm{m}$. Maintenance cost: $0.10 € / \mathrm{m} /$ year. Electrical resistance: $1.64 \times 10^{-4} \Omega / \mathrm{m}$. Rated current: 300 A. Maximum length of an LV line segment: 1,000 m. Nominal voltage: $230 \mathrm{~V}$. Minimum voltage: $220 \mathrm{~V}$. Maximum voltage: $240 \mathrm{~V}$.

- $M V$ lines (1 option). Cost: $7 € / \mathrm{m}$. Maintenance cost: $0.15 € / \mathrm{m} /$ year. Electrical resistance: $1.71 \times 10^{-5} \Omega / \mathrm{m}$. Rated current: 11,800 A. Nominal voltage: $13.2 \mathrm{kV}$. Minimum voltage: $12.6 \mathrm{kV}$. Maximum voltage: $13.8 \mathrm{kV}$.

- Transformers (2 options). Peak rating: $10 \mathrm{kVA}$ and $100 \mathrm{kVA}$. Cost: 2,000€ and 15,000€. Lifecycle: 10 years each. Efficiency: 0.95 .

- Building to shelter batteries and inverters at local and regional nodes. Fixed cost: 2,000€. Variable cost: $20 € /$ item sheltered.

Finally, the parameter $\alpha$ from the objective function, used to sum the lifecycle costs and weighted voltage drops, must be appropriately determined. The value selected should ensure that solution costs are not overly modified in order to minimise voltage drops; but to place generators at those locations that optimise supply quality, for the minimum cost solution. In this regard, as shown in Section 5, lifecycle cost differences between solutions can be around the unit order of magnitude, while for voltage drops they can reach the hundred order of magnitude (in the regional-scale). Consequently, $\alpha=0.001$ is chosen to ensure that voltage drops optimisation is not detrimental for lifecycle costs minimisation.

\section{Electrification system design}

In this section, the electrification system of the Jubera valley is studied. First, the local-scale model is used to design two local microgrid solutions for each village (Section 5.1). Then, the regional-scale model is used to design a regional microgrid solution (Section 5.2). Finally, the most appropriate electrification option is selected and a sensitivity analysis of demand growth is performed (Section 5.3). Complex combinatorial optimisation problems, such as the one focussed in this paper, can be solved using specialised software. In particular, IBM ILOG CPLEX 12.2 Optimizer is here used, on a PC 3.16 GHz Intel Core 2 Duo E8500 with 3.46 GB of RAM. CPLEX is a very powerful computational tool that has been used previously in related problems [Bliek et al., 2014]. 


\subsection{Local-scale study}

A local-scale design is performed separately for each village. Using the optimisation model developed in Section 3.1, two solutions are proposed in order to analyse the influence on the solution cost and configuration of locating generators at demand or local nodes:

- Generation at demand nodes $(G D N)$. A local microgrid supplies all the demand nodes, with generation located at one of these nodes, designed using the local-scale model with constraints (19) and (20).

- Generation at local nodes (GLN). A local microgrid supplies all the demand nodes, with generation located at one of the local nodes (Section 4.2), designed using the local-scale model with constraints (21) and (22).

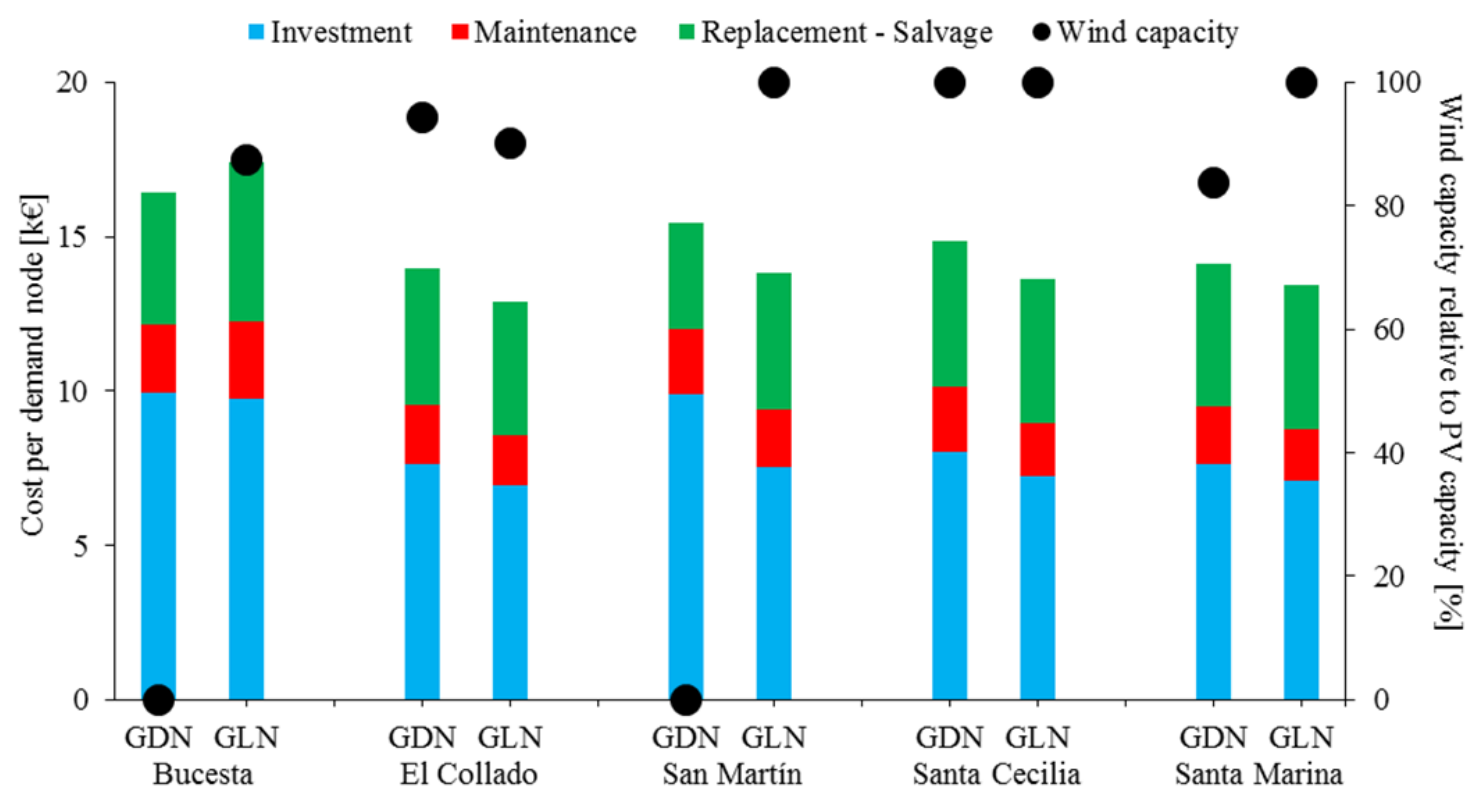

Figure 4. Solutions for each village and configuration (local-scale study)

The lifecycle cost for the solutions obtained is shown in Figure 4, distinguishing between investment, maintenance and replacement including salvage costs. Costs are displayed per demand node, instead of per village, to avoid comparing too differently sized bars. The energy contribution from wind turbines (wind capacity) relative to PV capacity is also shown.

Regarding project costs, the relationship between investment and lifecycle costs is generally similar: if the investment is higher for GDN over GLN, then so is the lifecycle cost. However, this link is not seen in Bucesta, since $G D N$ has a lower investment cost over $G L N$ but a higher lifecycle cost. Thus, the benefits of considering maintenance, replacement and salvage costs (in addition to investment costs), to provide a more accurate estimate of upfront and ongoing costs, is here demonstrated. Indeed, basing results only on investment costs could result in poor decisions being made, as upfront cheaper solutions can become more expensive when considering the entire project lifecycle. 
In terms of supply quality, Figure 5 shows how generators are placed at the centre of villages in $G D N$ configurations, in order to minimise voltage drops. These solutions improve upon those from previous works, where generators could well be placed at any demand node, as the wind and solar resources are the same within each village. Indeed, the local-scale model was solved for all the villages without including the term relating to voltage drops in the objective function. As a result of comparing such solutions and the GDN solutions, an average reduction on voltage drops of $33.1 \%$ was obtained. In addition, note that in the regional-scale study (Section 5.2), transformers are installed at such central locations for each village.

Finally, about the comparison between GDN and GLN configurations, results show how the local-scale model tends to obtain solutions that take advantage of high wind resource locations $(G L N)$, which are cheaper than the $G D N$ solutions, except for Bucesta. Indeed, when GDN microgrids are implemented, large wind turbines are deployed in El Collado, Santa Cecilia and Santa Marina. In some cases, a small PV capacity is used to cover expected shortfalls to reach the demand. In contrast, the electricity supply is completely based on PV panels in Bucesta and San Martín, as their wind resource is very low. When GLN microgrids are considered, wind turbines are mainly utilised for all villages, showing the suitability of the windy locations identified in Section 4.2. Indeed, although LV lines must be extended from local nodes to reach the villages, but smaller (and cheaper) wind turbines can be used for the same energy output. Only in Bucesta, with five houses and limited opportunities for economies of scale, the GDN cost is higher than the GLN one as the LV lines extension is not compensated by the smaller equipment used.

\subsection{Regional-scale study}

The regional-scale approach is analysed considering all villages together. Using the optimisation model developed in Section 3.2, a new configuration is proposed:

- Generation at regional nodes $(G R N)$. A regional MV microgrid supplies all the villages, with generation located at one of the regional nodes (Section 4.2) and MV lines for intervillage connections, designed using the regional-scale model.

Table 4 shows the lifecycle cost for the three solutions (GDN, GLN and GRN), distinguishing between investment, maintenance and replacement including salvage costs, as well as the percentage of energy coming from wind turbines. To enable comparison between the local and regional scales, the sum of the village costs is shown for the GDN and GLN approaches.

Table 4. Solutions for each configuration and demand scenario for the regional-scale study

\begin{tabular}{|l|r|r|r|}
\hline \multirow{2}{*}{ Solution } & \multicolumn{3}{c|}{ Configuration } \\
\cline { 2 - 4 } & \multicolumn{1}{|c|}{$\boldsymbol{G D N}$} & \multicolumn{1}{c|}{$\boldsymbol{G L N}$} & \multicolumn{1}{c|}{ GRN } \\
\hline Investment cost [k€] & 450 & 395 & 307 \\
\hline Maintenance cost [k€] & 107 & 95 & 233 \\
\hline Replacement incl. salvage cost [k€] & 226 & 242 & 153 \\
\hline Lifecycle cost (total) [k€] & 783 & 732 & 693 \\
\hline Energy from wind turbines [\%] & 56 & 96 & 96 \\
\hline
\end{tabular}


When comparing the local microgrids (GDN and GLN) and the regional microgrid (GRN), the lifecycle cost differences are noteworthy. The regional microgrid leads to very significant economies of scale, by using larger (and proportionally cheaper) wind turbines, benefiting from the very high wind potential at regional nodes. Thus, when comparing the GDN and GLN solutions, in the second option smaller wind turbines (or without PV panels) are used, since the demand to be covered at each village is approximately the same, but a higher energy output is supplied by wind turbines located at local nodes. When comparing the GLN and $G R N$ solutions, in the second option all villages demand is simultaneously supplied from very windy locations, so instead of using different wind turbines and PV panels at each village, the equipment is concentrated at a single location, taking advantage of economies of scale. In fact, as observed, the electrical supply for the regional microgrid $(G R N)$ is mainly based on wind energy, using PV technology to cover short-term deficits to reach the demand requirements. Thus, the suitability of the very windy regional nodes identified in Section 4.2 is shown.

\subsection{Final analysis and recommendations}

The general conclusion of this investigation is that local and regional-scale models allow for design adequate solutions. On one hand, results are based on lifecycle costs, taking informed decisions, and distribution schemes minimise microgrid losses. On the other hand, high wind resource locations, far from the villages, can be considered to reduce costs while optimising supply quality. Thus, the GRN configuration is recommended for implementation in the Jubera valley (Figure 5). This solution consists of a regional microgrid supplied by three wind turbines $(2 \times 30 \mathrm{~kW}$ and $1 \times 10 \mathrm{~kW})$ and four PV panels (250 W each), located at a regional node. An additional building is constructed close to this node to shelter batteries and inverters. Electricity is distributed, first, to villages through MV lines and then to individual houses through LV lines. Transformers are installed at the villages to transform MV into LV at the demand nodes that minimise voltage drops for each local microgrid.

As observed, the final solution is mainly based on the wind generation. In this regard, as the wind resource may have a significant variability, it must be noted that equipment has been sized assuming the least favourable conditions (in terms of energy resources and consumption peaks), and will presumably be oversized for better condition periods. In addition, batteries have been sized according to the self-sufficiency period, which was conceived considering the wind variability. Therefore, the solution is expected to efficiently cover the demand. Nevertheless, in order to reinforce and diversify generation, part of the costs saved by implementing configuration GRN instead of GDN or GLN, could be used, at the discretion of the project promoter, to install additional PV panels after project implementation, should enduser demand increase, thus improving security of supply. 

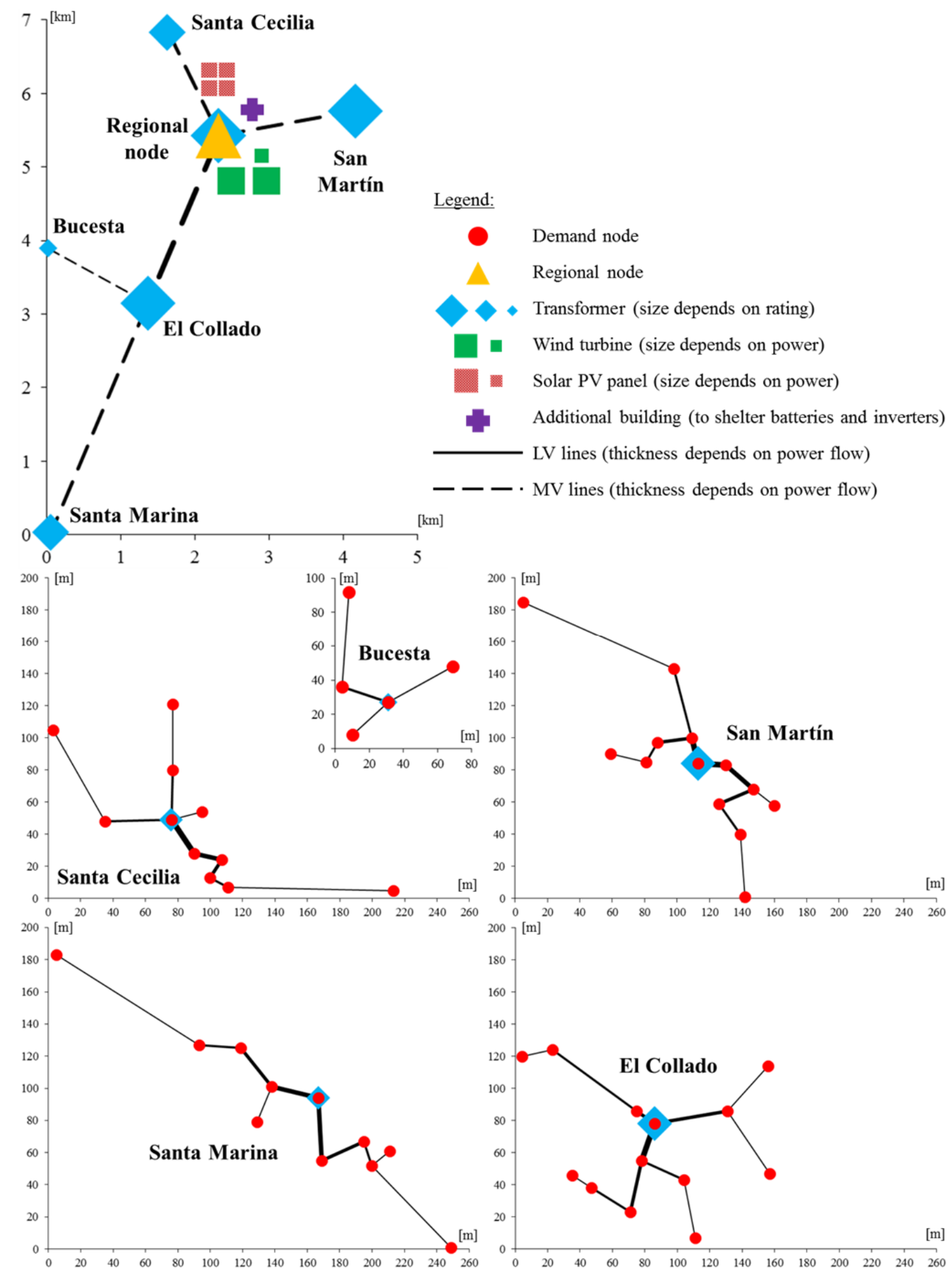

Figure 5. Electrification system configuration proposed for the Jubera Valley

Finally, a sensitivity analysis of the demand was performed in order to ensure the robustness of the solution chosen against future demand growth (Table 5). To do so, three demand scenarios were defined:

o Current: energy $3 \mathrm{kWh} /$ day; peak power $1.15 \mathrm{~kW}$; self-sufficiency 3 days.

o Medium: energy $5 \mathrm{kWh}$ /day; peak power $2.30 \mathrm{~kW}$; self-sufficiency 5 days.

o High: energy $7 \mathrm{kWh} /$ day; peak power $3.45 \mathrm{~kW}$; self-sufficiency 7 days. 
Table 5. Sensitivity analysis of demand, lifecycle cost of each solution [k€].

\begin{tabular}{|c|l|r|r|r|}
\hline \multirow{2}{*}{$\begin{array}{c}\text { Demand } \\
\text { scenario }\end{array}$} & \multicolumn{1}{|c|}{ Solution } & \multicolumn{3}{|c|}{ Configuration } \\
\cline { 3 - 5 } & & $\boldsymbol{G D N}$ & \multicolumn{1}{|c|}{$\boldsymbol{G L N}$} & \multicolumn{1}{c|}{$\boldsymbol{G R \boldsymbol { N }}$} \\
\hline \multirow{2}{*}{ Current } & Lifecycle cost (total) [k€] & 783 & 732 & 693 \\
\cline { 2 - 5 } & Energy from wind turbines [\%] & 56 & 96 & 96 \\
\hline \multirow{2}{*}{ Medium } & Lifecycle cost (total) [k€] & 1,691 & 1,549 & 1,213 \\
\cline { 2 - 5 } & Energy from wind turbines [\%] & 54 & 98 & 100 \\
\hline \multirow{2}{*}{ High } & Lifecycle cost (total) [k€] & 2,845 & 2,712 & 1,904 \\
\cline { 2 - 5 } & Energy from wind turbines [\%] & 53 & 91 & 99 \\
\hline
\end{tabular}

The results confirm that the $G R N$ solutions are always the best option in terms of minimum lifecycle cost, whatever the demand scenario. In addition, cost differences increase when the demand requirement is higher. Thus, for the current scenario, the cost difference between the GLN and GRN solutions is $5.3 \%$, while the value rises to $21.7 \%$ and $29.8 \%$ for the medium and high scenarios, respectively. Consequently, if the Local Administration expectations regarding the repopulation plan are met, the electricity demand will presumably grow and the regional microgrid will always be the cheapest option, confirming the GRN solution suitability. In addition, the relative energy contribution from wind turbines in $G R N$ is almost the same for the three scenarios and the configuration (generators location and nodes connection) remains unchanged. Therefore, solution robustness is confirmed as the regional microgrid generating from regional nodes is seen as the best configuration for all demand scenarios.

\section{Conclusion}

In this work, a two-scale design procedure is proposed to design regional renewable energybased electrification projects in a rural context. In order to find the solution, first, an electrification microgrid is designed for each village within the region and, then, a regional microgrid connecting the villages is conceived. To do so, two mathematical models are developed, aiming to minimise the combined investment, maintenance, replacement and salvage costs over the project lifecycle, as well as the voltage profile to optimise supply quality. The first model focuses on the local-scale to design independent projects for each village, using LV connections between nodes. In addition, while the solar resource is considered uniform, the wind resource is highly variable, so the possibility of generating at windy locations in the village surroundings (local nodes) is included. The second model focuses on the regional-scale to propose solutions considering a set of villages together, using MV lines for inter-village connections and generating at very windy locations within a central zone (regional nodes).

The two-scale design procedure is used to design the electrification system for five small villages in Jubera Valley (La Rioja, Northern Spain); according to a Local Administration request to promote electrification as a means for rural development. Information about the villages is firstly gathered: the electrical demand requirements are assessed, the energy resources (wind and solar) are evaluated, and equipment available in the market is identified. Using the mathematical models, three solutions are generated: a local microgrid for each 
village with generation at demand nodes $(G D N)$, a local microgrid for each village with generation at local nodes $(G L N)$, and a regional microgrid for the villages with generation at regional nodes $(G R N)$. In short, studying lifecycle costs instead of only investment costs has value, since upfront cheaper solutions can become more expensive when considering lifecycle costs. Supply quality, through minimisation of microgrid voltage drops, can be optimised without cost increases. Solutions including distant locations with a high wind resource potentially reduce the project costs, as large (and proportionally cheaper) wind turbines can be used. Finally, but importantly, a regional microgrid including all villages is, in the considered case, the cheapest option and reinforces inter-village organisation and communication. Therefore, a regional microgrid, using MV lines between villages and LV lines within them, with generation at very windy zones on a mountain hill in the centre of the region, is proposed for the Jubera Valley.

This study reinforces the idea of using electricity to promote rural development while using local renewable energy resources. Microgrids can play an important role as they allow costs to be reduced while optimising supply quality. In addition, considering regional-scale initiatives (instead of independent projects) can be beneficial for reducing costs through economies of scale and strengthening population organisation. As future research, a comprehensive MILP model (simultaneously including the local and regional scales) could be developed, analysing MILP-based heuristics for its resolution, for example based on a relax and fix approach.

\section{Appendix A. Regional-scale objective function}

The objective function (A1) minimises lifecycle costs (investment, maintenance, replacement and salvage) while optimising the weighted supply quality.

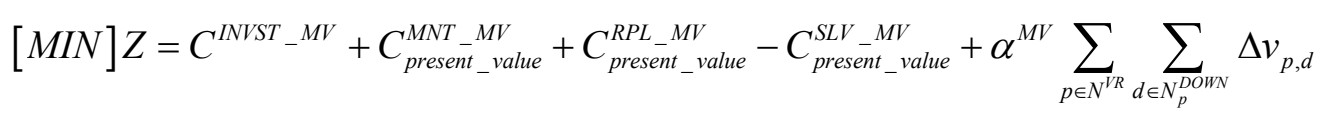

Investment costs (A1.1) represent the purchase of wind turbines, solar PV panels, batteries, inverters, transformers, LV lines, MV lines and additional buildings installed.

$$
\begin{aligned}
& C^{I N V S T_{-} M V}=\sum_{p \in N^{R E G}} \sum_{w \in N^{W T}} x_{p, w}^{W T} C_{w}^{W T}{ }^{\text {invst }}+\sum_{p \in N^{R E G}} \sum_{s \in N^{P V}} x_{p, s}^{P V} C_{s}^{P V}{ }^{i n v s t}+\sum_{p \in N^{R E G}} \sum_{b \in N^{B A T}} x_{p, b}^{B A T} C_{b}^{B A T_{-} i n v s t}+ \\
& \sum_{p \in N^{R E G}} \sum_{i \in N^{I N V}} x_{p, i}^{I N V} C_{i}^{I N V}{ }^{i n v s t}+\sum_{p \in N^{v R}} \sum_{t \in N^{T R F}} x_{p, t}^{T R F} C_{t}^{T R F_{-} i n v s t}+ \\
& \sum_{p \in N^{V L L}} C_{p}^{V I L \_i n v s t}+\sum_{p \in N^{v R}} \sum_{d \in N_{p}^{D O W N}} \sum_{l \in N^{M V}} u_{p, d, l}^{M V} D_{p, d}^{N O D E} C_{l}^{M V \_i n v s t}+ \\
& \sum_{p \in N^{R E G}}\left[u_{p}^{G E N} C^{B U I L D_{-} f x}+\left(\sum_{b \in N^{B A T}} x_{p, b}^{B A T}+\sum_{i \in N^{N V}} x_{p, i}^{I N V}\right) C^{B U I L D_{-} v a r}\right]
\end{aligned}
$$

Maintenance costs (A1.2) represent the yearly expense to ensure wind turbines, solar PV panels, batteries, LV lines and MV lines functioning (cleaning, repairs, etc.). 


$$
\begin{aligned}
& C_{\text {present_value }}^{M N T_{\text {_M }}}=\left\{\sum_{p \in N^{R E G}} \sum_{w \in N^{W T}} x_{p, w}^{W T} C_{w}^{W T \_m n t}+\sum_{p \in N^{R E G}} \sum_{s \in N^{P V}} x_{p, S^{P V}}^{P V} C_{s}^{P V_{-} m n t}+\sum_{p \in N^{R E G}} \sum_{b \in N^{B A T}} x_{p, b}^{B A T} C_{b}^{B A T}{ }^{m n t}+\right. \\
& \left.\sum_{p \in N^{V L L}} C_{p}^{V I L_{-} m n t}+\sum_{p \in N^{V R}} \sum_{d \in N_{p}^{D O W N}} \sum_{l \in N^{M V}} u_{p, d, l}^{M V} D_{p, d}^{N O D E} C_{l}^{M V-m n t}\right\} \\
& \left\{\left(\frac{1+\rho^{I N T}}{\rho^{D I S C}-\rho^{I N T}}\right)\left[1-\left(\frac{1+\rho^{I N T}}{1+\rho^{D I S C}}\right)^{L^{P R J}}\right]\right\}
\end{aligned}
$$

Replacement costs (A1.3) represent substitutions in wind turbines, solar PV panels, batteries, inverters and transformers exceeding their lifecycle.

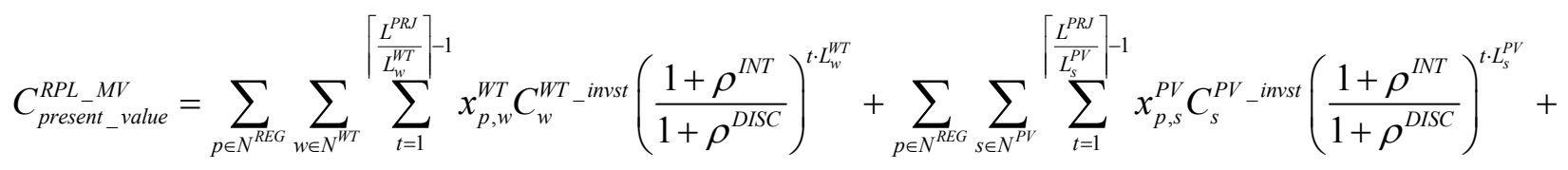

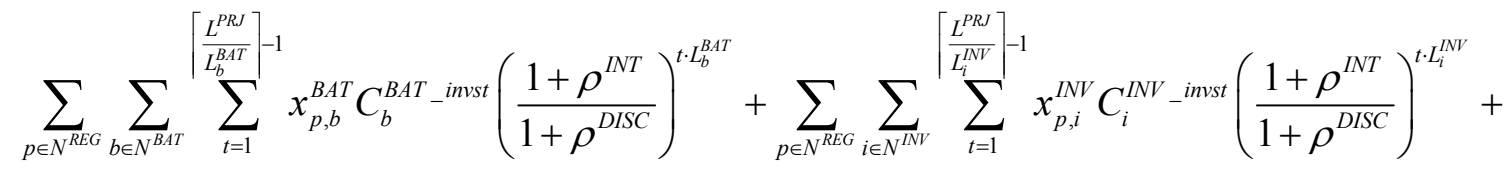

$$
\begin{aligned}
& \sum_{p \in N^{v R}} \sum_{j \in N^{T R F}} \sum_{t=1}^{\left[\frac{L^{P R S}}{L_{j}^{T R F}}{ }^{-1}\right.} x_{p, j}^{T R F} C_{j}^{T R F}-i n v s t\left(\frac{1+\rho^{I N T}}{1+\rho^{D I S C}}\right)^{t \cdot L_{j}^{T R F}}
\end{aligned}
$$

Salvage costs (A1.4) represent the marginal value of wind turbines, solar PV panels, batteries, inverters and transformers at project end.

$$
\begin{aligned}
& C_{\text {present_value }}^{\text {SLV_MV }}=\left\{\sum_{p \in N^{R E G}} \sum_{w \in N^{W T}} x_{p, w}^{W T} C_{w}^{W T \_ \text {invst }}\left(\left\lceil\frac{L^{P R J}}{L_{w}^{W T}}\right]-\frac{L^{P R J}}{L_{w}^{W T}}\right)+\sum_{p \in N^{R E G}} \sum_{s \in N^{P V}} x_{p, s}^{P V} C_{s}^{P V \_ \text {invst }}\left(\left\lceil\frac{L^{P R J}}{L_{s}^{P V}}\right\rceil-\frac{L^{P R J}}{L_{s}^{P V}}\right)+\right. \\
& \sum_{p \in N^{R E G}} \sum_{b \in N^{B A T}} x_{p, b}^{B A T} C_{b}^{B A T \_}{ }_{-}^{i n v s t}\left(\left\lceil\frac{L^{P R J}}{L_{b}^{B A T}}\right\rceil-\frac{L^{P R J}}{L_{b}^{B A T}}\right)+\sum_{p \in N^{R E G}} \sum_{i \in N^{I N V}} x_{p, i}^{I N V} C_{i}^{I N V_{-} i n v s t}\left(\left\lceil\frac{L^{P R J}}{L_{i}^{I N V}}\right\rceil-\frac{L^{P R J}}{L_{i}^{I N V}}\right) \\
& \left.\sum_{p \in N^{v R}} \sum_{t \in N^{T R F}} x_{p, t}^{T R F} C_{t}^{T R F_{-} i n v s t}\left(\left[\frac{L^{P R J}}{L_{t}^{T R F}}\right\rceil-\frac{L^{P R J}}{L_{t}^{T R F}}\right)\right\}\left(\frac{1+\rho^{I N T}}{1+\rho^{D I S C}}\right)^{L^{P R J}}
\end{aligned}
$$

\section{Acknowledgment}

This project was funded by UCD Energy21, co-financed through the Marie Curie FP7-PEOPLE-2013-COFUND program, the Spanish Ministry of Science and Innovation (project ENE2015-67253-R), and the Department of Management (DOE) of the Universitat Politènica de Catalunya (UPC). The authors are very grateful to the major of Jubera valley for all his support and assistance during the development of this research. 


\section{References}

Abdul-Salam Y, Phimister E. How effective are heuristic solutions for electricity planning in developing countries. Socio-Economic Planning Sciences 55 (2016) 14-24.

Agarwal N, Kumar A. Optimisation of grid independent hybrid PV-diesel-battery system for power generation in remote villages of Uttar Pradesh, India. Energy for Sustainable Development 17 (2013) 210-219.

Azimoh CL, Klintenberg P, Mbohwa C, Wallin F. Replicability and scalability of mini-grid solution to rural electrification programs in sub-Saharan Africa. Renewable Energy 106 (2017) 222-231.

Bahramara S, Parsa-Moghaddam M, Haghifam MR. Optimal planning of hybrid renewable energy systems using HOMER: a review. Renewable and Sustainable Energy Reviews 62 (2016) 609-620.

Barnes M, Kondoh J, Asano H, Oyarzabal J, Ventakaramanan G, Lasseter R, Hatziargyriou N, Green T. Realworld microgrids - an overview. IEEE International Conference on System of Systems Engineering (2007).

Bhattacharjee S, Acharya S. PV-wind hybrid power option for a low wind topography. Energy Conversion and Management 89 (2015) 942-954.

Bhoyar R, Bharatkar S. Potential of MicroSources. Renewable energy sources and application of microgrids in rural areas of Maharashtra state India. Energy Procedia 14 (2012) 2012-2018.

Bliek C, Bonami P, Lodi A. Solving Mixed-Integer Quadratic Programming problems with IBM-CPLEX: a progress report. Proceedings of the $26^{\text {th }}$ RAMP Symposium, Tokyo, Japan (2014).

Bortolini M, Gamberi M, Graziani A, Pilati F. Economic and environmental bi-objective design of an off-grid photovoltaic-battery-diesel generator hybrid energy system. Energy Conversion and Management 106 (2015) 1024-1038.

Bueno C, Carta JA. Wind powered pumped hydro storage systems, a means of increasing the penetration of renewable energy in the Canary Islands. Renewable and Sustainable Energy Reviews 10 (2006) 312-340.

Castilla M, Gomez M, Mercado P, Moreira C, Negroni JJ, Sosa J, Zambroni de Sousa AC. The growing state of distributed generation and microgrids in the Ibero-American region: a view from the RIGMEI network. Proceedings of the 2014 IEEE PES TDLA, Medellín, Colombia (2014).

Chade D, Miklis T, Dvorak D. Feasibility study of wind-to-hydrogen system for Artic remote locations Grimsey island case study. Renewable Energy 76 (2015) 204-211.

Chmiel Z, Bhattacharyya SC. Analysis of off-grid electricity system at Isle of Eigg (Scotland): lessons for developing countries. Renewable Energy 81 (2015) 578-588.

Colmenar-Santos A, Campíñez-Romero S, Pérez-Molina C, Castro-Gil M. Profitability of grid-connected photovoltaic facilities for household electricity self-sufficiency. Energy Policy 51 (2012) 749-764.

Dalton GJ, Lockington DA, Baldock TE. Case study feasibility analysis of renewable energy supply options for small to medium-sized tourist accommodations. Renewable Energy 34 (2009) 1134-1144.

Díaz P, Arias CA, Gómez-González M, Sandoval D, Lobato R. Solar home system electrification in dispersed rural areas: a 10-year experience in Jujuy, Argentina. Progress in Photovoltaics: Research and Applications 21 (2013) 297-307.

Domenech B, Ferrer-Martí L, Lillo P, Pastor R, Chiroque J. A community electrification project: combination of microgrids and household systems fed by wind, PV or micro-hydro energies according to micro-scale resource evaluation and social constraints. Energy for Sustainable Development 23 (2014) 275-285.

Domenech B, Ferrer-Martí L, Pastor R. Including management and security of supply constraints for designing stand-alone electrification systems in developing countries. Renewable Energy 80 (2015) 359-369.

Dufo-López R, Bernal-Agustín JL, Yusta-Loyo JM, Domínguez-Navarro JA, Ramírez Rosado IJ, Lujano J, Aso I. Multi-objective optimisation minimising cost and life cycle emissions of stand-alone PV-wind-diesel systems with batteries storage. Applied Energy 88 (2011) 4033-4041.

Ferrer-Martí L, Garwood A, Chiroque J, Ramirez B, Marcelo O, Garfí M, Velo E. Evaluating and comparing three community small-scale wind electrification projects. Renewable and Sustainable Energy Reviews 16 (2012) 5379-5390.

Ferrer-Martí L, Domenech B, García-Villoria A, Pastor R. A MILP model to design hybrid wind-photovoltaic isolated rural electrification projects in developing countries. European Journal of Operational Research 226 (2013) 293-300. 
Gamarra C, Guerrero JM. Computational optimisation techniques applied to microgrids planning: a review. Renewable and Sustainable Energy Reviews 48 (2015) 413-424.

Gandini D, de Almeida AT. Direct current microgrids based on solar power systems and storage optimization, as a tool for cost-effective rural electrification. Renewable Energy 111 (2017) 275-283.

Giannoulis ED, Haralambopoulos DA. Distributed generation in an isolated grid: methodology of case study for Lesvos - Greece. Applied Energy 88 (2011) 2530-2540.

GIZ. Tools for mini-grid practitioners. German International Cooperation. Available at: https://cleanenergysolutions.org/training/tools-facilitate-mini-grid-deployment. Last access: 07/03/2017.

Gueymard CA, Wilcox SM. Assessment of spatial and temporal variability in the US solar resource from radiometric measurements and predictions from models using ground-based or satellite data. Solar Energy 85 (2011) 1068-1084.

Hoque N, Kumar S. Performance of photovoltaic micro utility systems. Energy for Sustainable Development 17 (2013) 424-430.

Hossain E, Kabalci E, Bayindir R, Perez R. Microgrid testbeds around the world: state of art. Energy Conversion and Management 86 (2014) 132-153.

Huang R, Low SH, Topcu U, Chandi KM. Optimal design of hybrid energy system with PV/wind turbine/storage: a case study. International Conference on Smart Grid Communications (2011) 511-516.

IDAE. Wind Atlas of Spain. Institute for Diversification and Energy Savings. Available at: http://atlaseolico.idae.es. Last access: 27/11/2016.

INE. List of place name: population of the continuous municipal register by population unit. National Institute of Statistics, Spain (2014).

Katiraei F, Mauch K, Dignard-Bailey L. Integration of photovoltaic power systems in high-penetration clusters for distribution networks and mini-grids. International Journal of Distributed Energy Resources 3 (2007) 207-223.

Khatib T, Ibrahim IA, Mohamed A. A review on sizing methodologies of photovoltaic array and storage battery in a standalone photovoltaic system. Energy Conversion and Management 120 (2016) 430-448.

Koussa DS, Koussa M, Hadji S. Technical and economic study of a stand-alone wind energy system for mountainous rural area electrification in Algeria. Proceedings of the $5^{\text {th }}$ International Renewable Energy Congress (IREC), Hammamet, Tunisia (2014).

Krishna KS, Kumar KS. A review on hybrid renewable energy systems. Renewable and Sustainable Energy Reviews 52 (2015) 907-916.

Lambert TW, Hittle DC. Optimisation of autonomous village electrification systems by simulated annealing. Solar Energy 68 (2000) 121-132.

NASA. Surface meteorology and solar energy. A renewable energy resource web site (release 6.0). Available at: https://eosweb.larc.nasa.gov/sse/. Last access: 12/01/2017.

Pereira MG, Sena JA, Freitas MAV, da Silva NF. Evaluation of the impact of access to electricity: a comparative analysis of South Africa, China, India and Brazil. Renewable and Sustainable Energy Reviews 15 (2011) $1427-1441$

Ranaboldo M, Domenech B, Vilar D, Ferrer-Martí L, Pastor R, García-Villoria A. Renewable energy projects to electrify rural communities in Cape Verde. Applied Energy 118 (2014) 280-291.

Rezaei M, Dowlatabadi H. Off-grid: community energy and the pursuit of self-sufficiency in British Columbia's remote and First Nations communities. Local Environment - The International Journal of Justice and Sustainability (2015).

Rojas-Zerpa JC, Yusta JM. Application of multicriteria decision methods for electric supply planning in rural and remote areas. Renewable and Sustainable Energy Reviews 52 (2015) 557-571.

Ruiz-Romero S, Colmenar-Santos A, Gil-Ortego R, Molina-Bonilla A. Distributed generation: the definitive boost for renewable energy in Spain. Renewable Energy 53 (2013) 354-364.

Schnitzer D, Lounsbury DS, Carvallo JP, Deshmukh R, Apt J, Kammen DM. Microgrids for rural electrification: a critical review of best practices based on seven case studies. United Nations Foundation (2014).

SE4All. Sustainable energy for all. 2014 Annual Report. International Renewable Energy Agency, United Nations: Vienna (2014).

Singh S, Singh M, Kaushik SC. Feasibility study of an islanded microgrid in rural area consisting of PV, wind, biomass and battery energy storage system. Energy Conversion and Management 128 (2016) 178-190. 
Thiam DR. Renewable decentralised in developing countries: appraisal from microgrids project in Senegal. Renewable Energy 35 (2010) 1615-1623.

Ubilla K, Jiménez-Estévez GA, Hernádez R, Reyes-Chamorro L, Hernández Irigoyen C, Severino B, PalmaBehnke R. Smart microgrids as a solution for rural electrification: ensuring long-term sustainability through cadastre and business models. IEEE Transactions on Sustainable Energy 5 (2014) 1310-1318.

Wang H, Huang J. Cooperative planning of renewable generation for interconnected microgrids. IEEE Transactions on Smart Grid 7(5) (2016) 2486-2496.

Wang H, Huang J. Joint investment and operation of microgrid. IEEE Transactions on Smart Grid 8(2) (2017a) 833-845.

Wang H, Huang J. Incentivizing energy trading for interconnected microgrids. IEEE Transactions on Smart Grid (2017b). DOI: 10.1109/TSG.2016.2614988.

Zhou W, Lou C, Li Z, Lu L, Yang H. Current status of research on optimum sizing of stand-alone hybrid solarwind power generation systems. Applied Energy 87 (2010) 380-389. 